\title{
Cellular retinol binding protein-1 expression in endometrial hyperplasia and carcinoma: diagnostic and possible therapeutic implications
}

Augusto Orlandi ${ }^{1}$, Amedeo Ferlosio ${ }^{1}$, Alessandro Ciucci ${ }^{1}$, Arianna Francesconi ${ }^{1}$, Beatriz Lifschitz-Mercer ${ }^{2}$, Giulio Gabbiani ${ }^{3}$, Luigi G Spagnoli ${ }^{1}$ and Bernard Czernobilsky ${ }^{4}$

${ }^{1}$ Institute of Anatomic Pathology, Tor Vergata University, Rome, Italy; ${ }^{2}$ Institute of Pathology, Tel Aviv Medical Centre, Tel Aviv, Israel; ${ }^{3}$ Institute of Pathology and Immunology, University of Geneva, Geneva, Switzerland and ${ }^{4}$ PATHO-LAB Laboratories, NESS-Ziona, Israel

\begin{abstract}
Cellular retinol binding protein-1 (CRBP-1) contributes to the maintenance of the differentiative state of endometrial glandular cells through the regulation of bioavailability of retinol and derivatives, but its role in endometrial oncogenetic process remains unclear. Antibodies to CRBP-1, estrogen and progesterone receptors (ER and PR) were applied to paraffin sections of proliferative $(n=10)$ and secretory endometrium $(n=9)$, and to endometrial polyps $(n=6)$, simple $(n=7)$, complex $(n=3)$ and atypical endometrial hyperplasias $(n=9)$ as well as to 47 endometrioid carcinomas of different histological grade (G) (G1, $n=18 ; G 2, n=19 ; G 3, n=10)$. Four serous and two clear cell carcinomas were also examined. In glandular cells, CRBP-1 positivity was mainly cytoplasmic and rarely in the nuclei. CRBP-1 immunodetection was weakly positive in proliferative and low and focal in secretory endometrium and higher in atypical as compared to simple and complex hyperplasias. CRBP1 expression in G1 endometrioid carcinomas was similar to that in atypical hyperplasias. In the latter, the highest CRBP-1 expression was observed in areas of squamous differentiation. Semiquantitative evaluation revealed a significant decrease of cytoplasmic CRBP-1 immunoreactivity with the increase of tumor grade. Among G3 endometrioid carcinomas, 60\% were CRBP-1 negative, whereas the remaining cases showed a very low and focal positivity. Serous carcinomas were also CRBP-1 negative. When areas of different grading were present within the same tumor, less differentiated areas retained a lower CRBP-1 immunoreaction. The progressive decrease of CRBP-1 paralleled that of ER and PR immunodetection. RT-PCR in eight endometrioid carcinomas suggested a decrease of CRBP-1 with the increase of tumor grade also at transcriptional level. Our results indicate that CRBP-1 immunodetection may constitute an additional tool for histological grading of endometrial carcinoma. The CRBP-1 loss during the progression of endometrial cancer suggests a new potential target for pharmacological strategies aimed to counteract its progression by increased intracellular retinol bioavailability.
\end{abstract}

Modern Pathology (2006) 19, 797-803. doi:10.1038/modpathol.3800586; published online 31 March 2006

Keywords: CRBP-1; endometrial cancer; retinoid receptor; cell differentiation; endometrial hyperplasia

Retinol (the prototypic vitamin A) and its metabolites called retinoids play important physiologic roles in a wide range of biological processes and participate in the control of cell growth and differentiation. ${ }^{1-5}$ Intracellular retinoid bioavailability is regulated by the presence of specific recep-

Correspondence: Professor A Orlandi, MD, Department of Biopathology and Image Diagnostics, Institute of Anatomic Pathology, Tor Vergata University of Rome, Via Montpellier 1, Rome 00133, Italy.

E-mail: orlandi@uniroma2.it

Received 27 December 2005; revised 16 February 2006; accepted 20 February 2006; published online 31 March 2006 tors; among these, cellular-retinol-binding proteins (CRBPs), which are members of the fatty acidbinding proteins (FABP)/CRPB family and are prominent among mammals. ${ }^{6}$ CRBPs have an important role in the retinol metabolism presenting the ligand to specific enzymes. ${ }^{1,7}$ In humans, three CRBPs types have been described: CRBP- 1 is widely distributed through the body, whereas CRBP-2 is mainly restricted to the small intestine and CRBP-3 to the cardiac and skeletal muscle. ${ }^{8}$ CRBP- 1 is a 15000 Da cytosolic protein that regulates the uptake and subsequent esterification of retinol and its bioavailability. ${ }^{9}$ CRBP-1 acts as a 'chaperone' that 
prevents the interaction between retinol and intracellular enzymatic milieu. ${ }^{10}$

In normal human breast epithelium, CRBP-1 is uniformly expressed but appears downregulated in about $24 \%$ of breast cancers. ${ }^{11} \mathrm{~A}$ loss of CRBP-1 gene expression is also reported in human ovarian cancers and ovarian cancer cell lines. ${ }^{12}$ All together, these data suggest that a reduction of CRBP-1 expression significantly contributes to the oncogenetic process. ${ }^{13}$

In the endometrium, transcript analysis documents significant levels of CRBP-1 throughout the menstrual cycle, whereas those of CRBP-2 vary and possibly mediate the effects of ovarian steroids. ${ }^{14,15}$ The availability of a specific antibody ${ }^{16}$ allowed to establish that a CRBP-1 positive immunodetection is characteristic of endometrial decidual type stromal cells. ${ }^{17}$

Endometrial cancer represents the eighth commonest cause of death from cancer in the female population. ${ }^{18}$ The overall-5-year survival for endometrial cancer is around $80 \%$, but substantial prognostic differences exist between the different histological types of endometrial carcinomas. ${ }^{19}$ Endometrioid type represents about $80 \%$ of all endometrial carcinomas. ${ }^{19,20}$ Most endometriod carcinomas are well to moderately differentiated, ${ }^{20}$ with various degrees of endometrial type glandular differentiation, ${ }^{21}$ arise in a background of endometrial hyperplasia and are also known as type 1 endometrial carcinomas. ${ }^{19,22}$ About $10 \%$ of endometrial cancers are type 2 (high grade) lesions, are not estrogen driven and histologically include serous and clear cell carcinomas. ${ }^{19,20}$ Endometrioid carcinomas, from a molecular view point, as well as morphologically, usually resemble proliferative rather than secretory endometrium. ${ }^{23}$ In a previous study, we reported some preliminary observations documenting cyclically regulated CRBP-1 expression in normal endometrial epithelium, which was somehow more prominent in proliferative than in secretory glands. ${ }^{24}$ The present study deals with CRBP-1 expression in a series of endometrial hyperplasias and carcinomas. In the latter, we correlated CRBP-1 levels to tumor grade. According to our results, it appears that a loss of CRBP-1 expression is associated with the development of less differentiated endometrial carcinomas.

\section{Materials and methods}

\section{Specimens}

Tissue samples were obtained from diagnostic biopsies and operative procedures over the last 3 years (Institute of Pathology of Tor Vergata University and Patho-Lab Laboratories); 13 cases of simple hyperplasia without atypia, six cases of endometrial polyps, three cases of complex hyperplasia without atypia, nine cases of complex hyperplasia with atypia, 53 of endometrial carcino- mas, including 47 endometrioid carcinomas (Grade 1, $n=18$; Grade 2, $n=19$; Grade 3, $n=10$ ), two clear cell and four serous adenocarcinomas, were investigated. We also studied 10 biopsies of proliferative and nine of secretory endometrium. Grading was according to F.I.G.O. and WHO criteria (5). The mean age of patients with endometrial carcinoma was 61 years, with a minimum of 45 and a maximum of 79 years. In eight cases of large tumors (four G1, two G2 and two G3 endometrioid carcinomas), after intraoperatory diagnosis, small freshly excised samples were frozen in isopentane, cooled in liquid nitrogen and stored at $-80^{\circ} \mathrm{C}$. Experimental procedures were approved by local Ethical Committees.

\section{Morphological and Immunohistochemical Study}

Paraffin serial sections (4- $\mu$ m-thick) were stained with Hematoxylin-Eosin and used for immunohistochemistry. For the latter, after deparaffinization, blocking of endogenous peroxidase activity with $0.2 \% \mathrm{H}_{2} \mathrm{O}_{2}(20 \mathrm{~min})$ and incubation with normal goat serum ( $30 \mathrm{~min}$ ), sections were exposed for $1 \mathrm{~h}$ to a polyclonal rabbit anti-CRBP-1 (15) (1:100, furnished by G Gabbiani, Geneva, Switzerland), monoclonal antiestrogen (ER; clone 1D5, Ylem, Italy) and antiprogesteron receptors (PR; clone 1A6, Ylem). Before incubation with primary antibodies, heatmediated antigen retrieval with a solution of $10 \mathrm{mM}$ sodium citrate buffer ( $\mathrm{pH}$ 6.0) in a microwave oven (three cycles of $5 \mathrm{~min}$ ) was performed. Diaminobenzidine was used as final chromogen. All immunohistochemical procedures were performed at room temperature. Semiquantitative CRBP-1, ER and PR immunoreaction was estimated at $\times 200$ magnification in at least 10 fields by two the authors, who used a grading system in arbitrary units as follows: absent (0), low and focal (0.5), positive (weakly positive, $1+$; moderately positive, $2+$; strongly positive, $3+$ ). ${ }^{24}$ The interobserver reproducibility was $>95 \%$. For each case, the ratio of the score with the number of fields analyzed was calculated. Results were analyzed by means of Student's $t$-test. The differences were considered statistically significant for value of $P<0.05$.

\section{Reverse-Transcription Polymerase Chain Reaction}

Total RNA was extracted by TRIzol (Invitrogen, Carlsbad, CA, USA) according to manufacturer's instructions and the amount of RNA was determined by measuring $\mathrm{OD}_{260}$. RNA ( $\left.4 \mu \mathrm{m}\right)$ were digested with $1 \mathrm{U}$ of Amplification Grade DNAse I (Invitrogen) for $15 \mathrm{~min}$ at room temperature and the reaction was stopped by incubation with EDTA $25 \mathrm{mM}$ for $10 \mathrm{~min}$ at $65^{\circ} \mathrm{C}$. Reverse transcription was performed using random hexamers pdN 6 and SuperScript II (Invitrogen); samples were incubated at $37^{\circ} \mathrm{C}$ for $90 \mathrm{~min}$ and the reaction was heat-inactivated for the following 5 min. Negative controls were also prepared by 
omitting reverse transcriptase in the reaction mixture. The primers used for cDNA amplification were: 5'CGC TTG TGG CCA AAC TGG CTC C (sense) and 5'ACA CAT CCT GCT GAT TGG TTG $\mathrm{G}$ (antisense) for CRBP-1 and 5'CTT GTC TT TCA GCA AGG ACT GG (sense) and 5'CCT CCA TGA TGC TGC TTA CAT GTC (antisense) for $\beta 2$-microglobulin. Reaction conditions were: $5 \mathrm{~min}$ at $95^{\circ} \mathrm{C}, 35$ cycles each cycle consisting of $45 \mathrm{~s}$ at $95^{\circ} \mathrm{C}, 1 \mathrm{~min}$ at $60^{\circ} \mathrm{C}$ and $1 \mathrm{~min}$ at $72^{\circ} \mathrm{C}$, followed by further $5 \mathrm{~min}$ at $72^{\circ} \mathrm{C}$ for final elongation; amplicons were 486 and 157 base pairs, respectively.

\section{Results}

In normal proliferative endometrium, glandular cells displayed a weak CRBP-1 immunopositivity (Figure 1a), whereas in secretory endometrium their CRBP-1 staining was low and focal (Figure 1b). In simple (Figure 1c) and complex hyperplasias, CRBP-1 expression was almost similar to that of proliferative endometrium. This degree of CRBP-1 expression was retained in endometrial polyps (Figure 1d). In the latter and in simple hyperplasia, stromal fibrous tissue cells were only focally CRBP-1 positive and thick vessel walls negative, as previously reported. ${ }^{17}$

In atypical hyperplasia, CRBP-1 expression was more evident (Figure 1e) and similar to that detected in G1 endometrioid carcinomas (Figure 1f). The highest expression of CRBP-1 was observed in areas of squamous differentiation (Figure 1g). A decrease of CRBP-1 immunostaining was detected with the progressive increase of histological grade. In G2 carcinomas, CRBP-1 expression was less diffuse (Figure $1 \mathrm{~h}$ and i) and, in some glands, CRBP-1 positive neoplastic cells alternated with others displaying an absent CRBP-1 immunoreaction, in a sort of tumor 'cell mosaicism' (Figure 1j), suggesting a progressive loss of CRBP-1 expression. In G3 carcinomas, the positivity was low and focal or absent (Figure 1k and 1); 60\% of G3 endometrioid carcinomas as well as all serous carcinomas were CRBP-1 negative. Less differentiated areas in otherwise G1 or G2 endometrioid carcinomas retained a lower CRBP-1 expression (Figure 2). CRBP-1 immonodetection was low and focal in clear cell carcinomas.

Results of semiquantitative evaluation of CRBP-1 immunostaining in endometrial carcinomas are shown in Figure 3. CRBP-1 expression was higher in complex atypical compared to simple hyperplasia $(P<0.0009)$. CRBP-1 immunodetection decreased in less differentiated carcinomas with significant differences (G1 vs G2: $P<0.017$; G1 vs G3: $P<0.0004$ and G2 vs G3: $P<0.0009$, respectively). No statistical difference was observed comparing CRBP-1 expression in atypical hyperplasias and G1 carcinomas. In a more restricted number of cases, RT-PCR showed a decrease of CRBP-1 transcript content in
G3 endometrial as compared to G2 and G1 carcinomas (Figure 4).

In some G2 carcinomas, a nuclear CRBP-1 immunoreactivity was also observed but its frequency did not reflect that of cytoplasmic staining (data not shown). Nuclear CRBP-1 positivity was extremely rare in G1 and absent in G3 carcinomas.

As shown in Figure 5, CRBP-1 decreased expression in endometrial carcinomas associated with reduced staining for ER (G1 vs G2: $P<0.002$; G1 vs G3: $P<0.04$; G2 vs G3: $P<0.04)$ and $\mathrm{PR}$ expression (G1 vs G2: $P<0.02$; G1 vs G3: $P<0.0002$; G2 vs G3: $P<0.03)$. Examination of serial sections demonstrated a good correlation between overall CRBP-1 and ER and PR tissue expression in endometrial carcinomas (not shown).

\section{Discussion}

In the present study, we analyzed the expression of CRBP-1 in endometrial carcinomas in comparison with that of normal and hyperplastic endometrium. Our results showed that epithelial glandular CRBP-1 imunodetection in simple hyperplasia was weakly positive and similar to that of proliferative endometrial cells. CRBP-1 expression increased in atypical hyperplasia and this feature was retained in G1 carcinomas. Importantly, we observed a progressive decrease of CRBP-1 immunoreactivity in less differentiated endometrial carcinomas, with a low or absent CRBP-1 expression in G3 endometrioid carcinomas. CRBP-1 was completely absent in serous carcinomas as well as in clear cell carcinomas. Our findings suggest that CRPB-1 may represent an additional phenotypic marker for the grading of endometrial carcinomas in which other morphological parameters, including nuclear pleomorphism and/or architectural abnormalities, do not allow a univocal grading. In fact, in G2 carcinomas with focal less differentiated areas, the latter retained a lower or negative CRBP-1 expression. A similar mosaicism has been recently demonstrated in G2 endometrial carcinomas for MLH1 expression. $^{25}$ The striking overall difference in the expression of CRBP-1 in type I and type II endometrial carcinomas reflects the differences in their risk factors and molecular pathogenesis. ${ }^{26-28}$ Type I tumors display various alterations that may coexist, including microsatellite instability and PTEN, k-ras and $\beta$-catenin gene mutations. ${ }^{22,29-32}$ Type II tumors are usually not associated with estrogen stimulation or hyperplasia ${ }^{32}$ and are characterized by mutation of p53 tumor suppressor gene. ${ }^{33}$ The similar CRBP-1 expression in atypical hyperplasia and well-differentiated endometrioid carcinoma can be considered an additional proof of the close relationship of these two entities which has been well documented in the literature. Furthermore, atypical hyperplasia progresses to carcinoma in a high percentage of cases. ${ }^{30,34,35}$ The low or 
800
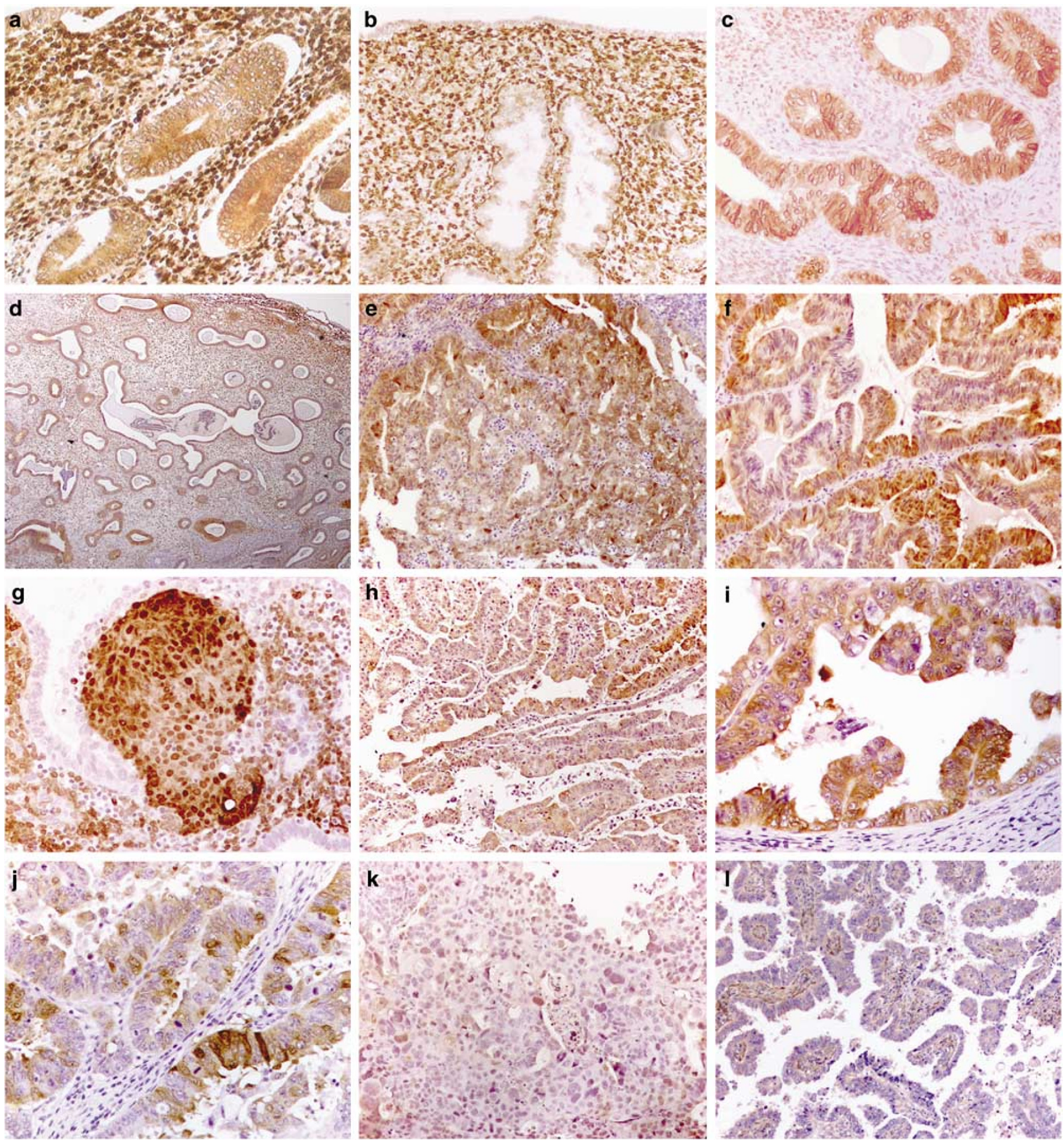

Figure 1 Immunohistochemical detection of CRBP-1 expression in normal and neoplastic endometrial cells. (a) A weakly cytoplasmic positivity is observed in proliferative endometrial glandular cells whereas (b) in secretory epithelium CRBP-1 is low, in contrast to endometrial stromal cells which are markedly positive. Cytoplasmatic CRBP-1 expression is present in (c) typical hyperplasia as well as in (d) endometrial polyps; in the latter, stromal cells are only focally CRBP-1 positive and thick vessel walls negative. CRBP-1 expression is more marked in (e) complex atypical hyperplasia as well as in (f) well-differentiated endometrioid carcinoma, particularly in (g) areas of squamous differentiation. (h and i) CRBP-1 expression is still evident in moderately differentiated carcinoma. (j) A detail of G2 carcinoma showing CRBP-1 positive glandular cells alternate with negative ones. (k) G3 endometrioid carcinoma shows a poor CRBP-1 expression, which is completely absent in (l) serous carcinoma. Original magnification, $\times 100$ for $\mathbf{d} ; \times 200$ for $\mathbf{c}, \mathbf{e}, \mathbf{f}, \mathbf{h}$ and $\mathbf{l}$; $\times 250$ for $\mathbf{a}$, $\mathbf{g}, \mathbf{i}, \mathbf{j}$ and $\mathbf{k}$.

absent CRBP-1 expression in serous and clear cell carcinomas further supports the distinct molecular pathogenetic pathways in type I as compared to type II endometrial carcinomas. ${ }^{2}$
The role of CRBP-1 in retinoid signaling during cancer progression has become relevant during the last years ${ }^{13}$ but it is far from being completely understood. In the uterus, CRBP-1 expression 

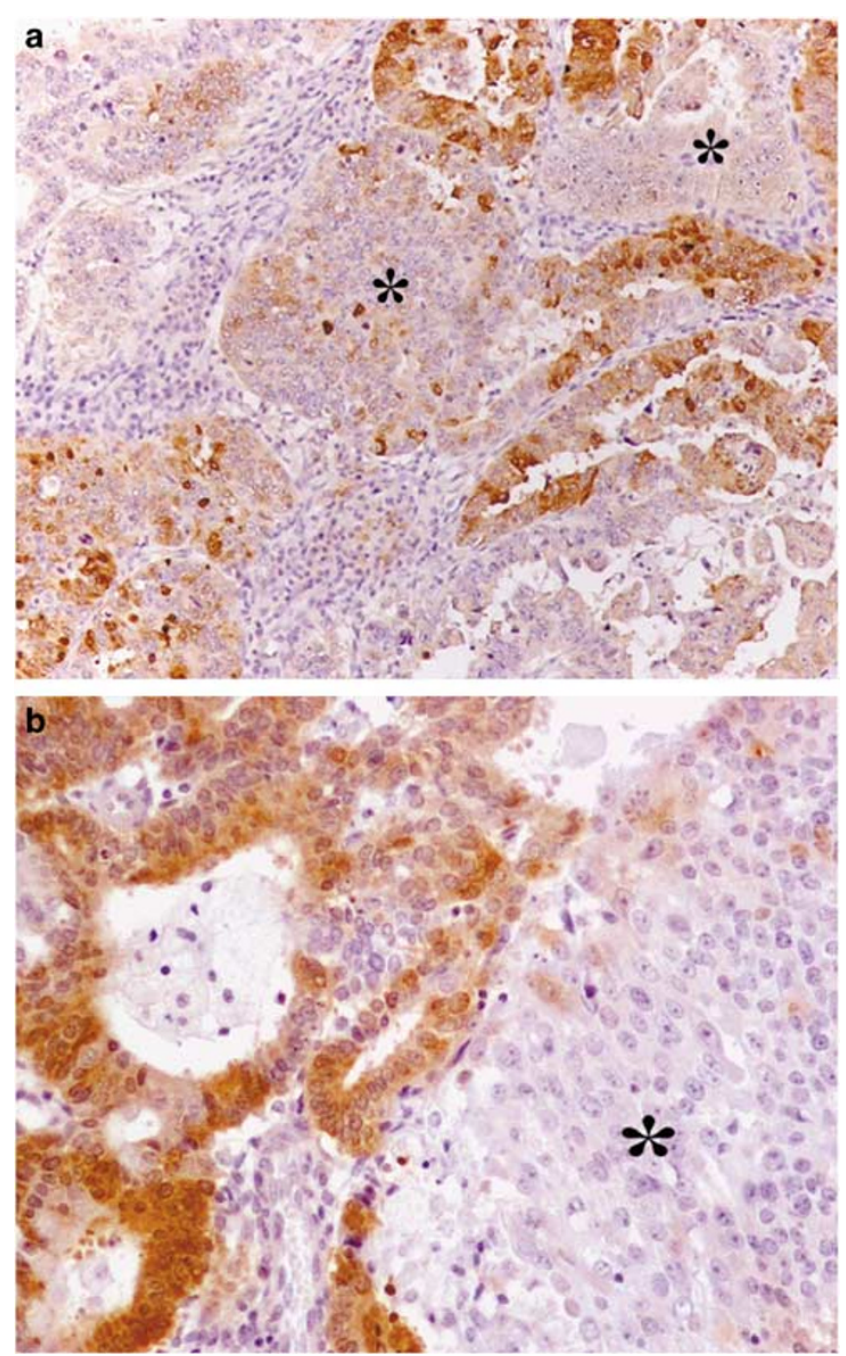

Figure 2 (a and b) In poorly differentiated areas $\left({ }^{*}\right)$ of an otherwise G2 endometrioid carcinoma, CRBP-1 expression is markedly reduced, whereas in adjacent more differentiated areas with a glandular pattern CRBP-1 expression is retained. Original magnification, $\times 200$ for $\mathbf{a}$; $\times 250$ for $\mathbf{b}$.

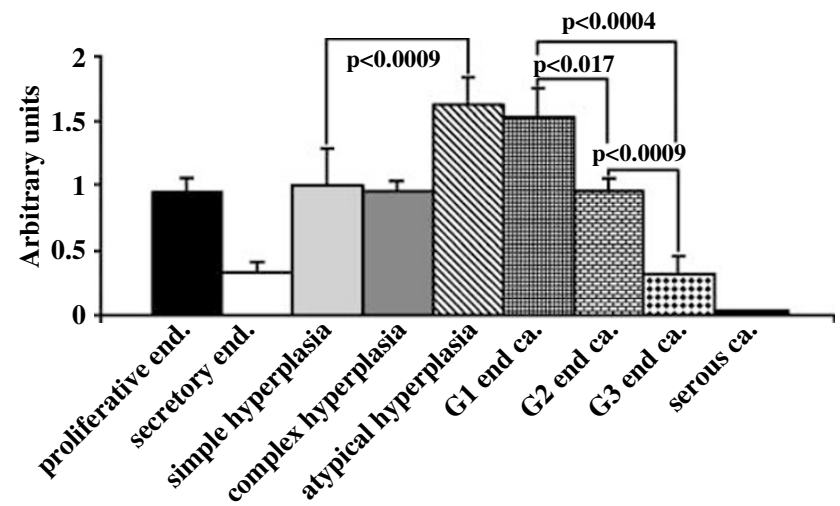

Figure 3 Bar graphs showing semiquantitative evaluation of CRBP-1 expression in proliferative and secretory endometrium (end.), simple, complex and atypical hyperplasia, well differentiated (G1), moderately differentiated (G2), poorly differentiated (G3) and serous carcinomas.

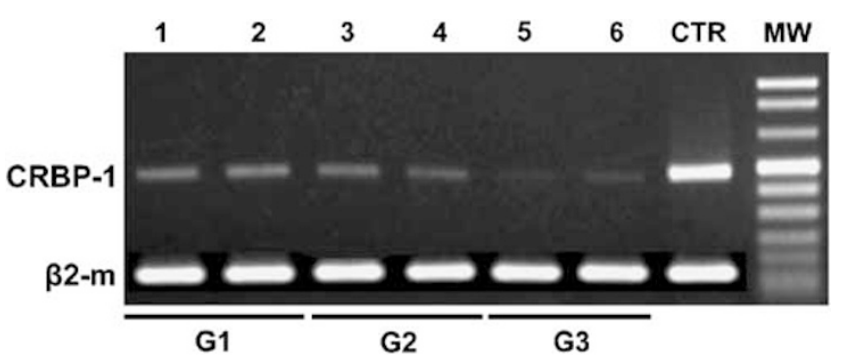

Figure 4 Demonstrative gel of CRBP-1 transcript level examinated by Reverse-transcriptase polymerase chain reaction. Transcript levels are progressively reduced in less differentiated endometrioid carcinomas; $\beta 2$ microglobulin $(\beta 2-\mathrm{m})$ is used as control gene.

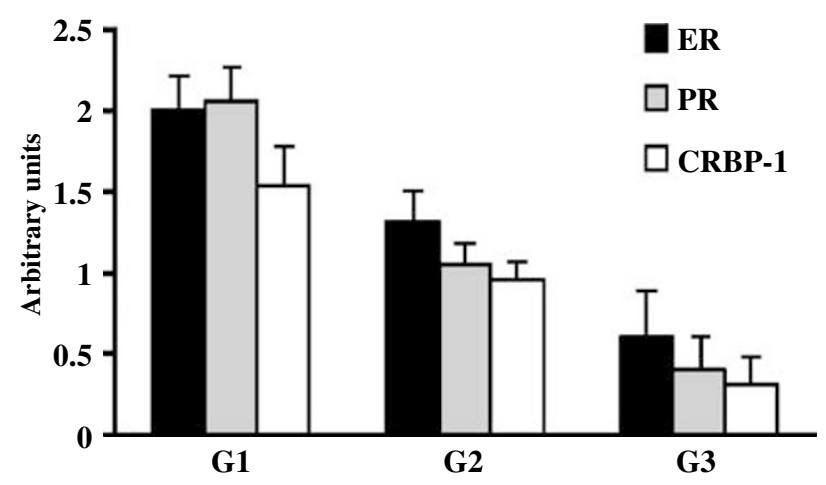

Figure 5 Bar graphs showing semiquantitative evaluation of CRBP-1, estrogen and progesterone receptor (ER and PR) expression in well differentiated (G1), moderately differentiated (G2) and poorly differentiated (G3) endometrioid carcinomas.

represents an important signal during normal implantation of the embryo. ${ }^{36}$ Decidual cells, isolated from the uterus and provided with retinol, synthesize and release retinoic acid in the medium. ${ }^{36}$ Endometrial epithelial cells differ in their retinoid physiology from stromal cells; since the latter appear to be more responsive to retinol than to retinoic acid. ${ }^{14}$ Differences in CRBP-1 expression may reveal the necessity to maintain higher concentrations of retinoic acid through the intracellular retinol conversion in endometrial epithelial cells to facilitate their differentiation. ${ }^{6,7,14}$

Our present data did not allow to explain why CRBP-1 expression is increased in atypical hyperplasia compared to proliferative endometrial epithelium. Nevertheless, some considerations can be made. In squamous epithelium of the cervix, CRBP1 expression is mainly limited to basal layers and varies according to hormonal stimulation ${ }^{37}$ and increases with the presence of dysplasia. ${ }^{38}$ In atypical hyperplastic endometrium, increased CRBP-1 expression may represent the presence of an exaggerate epithelial response to estrogen stimulation, which requires an increase in the biosynthesis and metabolism of retinol. ${ }^{7}$ Our results in endometrial carcinoma are in agreement with 
previous reports documenting a loss of CRBP-1 expression in carcinoma of the breast ${ }^{39}$ and ovarian cancers. $^{12}$ Nevertheless, present data alone do not suffice to clarify how the loss of CRBP-1 expression relates to endometrial cancer progression. CRBP-1 downregulation occurring with cancer progression is likely to contribute to the loss of cell differentiation and control of proliferation. ${ }^{11}$ Reduced levels of CRBP-1 may interfere with retinoic acid metabolism by reducing retinol bioavailability and blocking retinol esters. ${ }^{6}$ One of the possible mechanisms of CRBP-1 silencing is hypermethylation-associated inactivation, as reported in breast ${ }^{40}$ and prostate cancer $^{41}$ but also in several cancer cell lines in vitro. ${ }^{42}$ Moreover, the parallel and progressive decrease in ER and PR status and CRBP-1 in less differentiated endometrioid carcinomas further supports a link between these receptor patterns in type I endometrial carcinomas. ${ }^{43}$ The role of CRBP-1 in the regulation of rationed bioavailability ${ }^{1,2,6,11}$ suggests that during the progression of type 1 endometrial carcinogenesis the prodifferentiative function of retinoids is progressively lost. The absence of CRBP-1 in less differentiated carcinomas is likely to result in a sort of intracellular hypovitaminosis, since normal or even excess of retinol levels cannot promote epithelial differentiation. ${ }^{13}$ Conversely, dietary retinal intake can influence the extent of CRBP-1 silencing in human cancer. ${ }^{42}$ The maintenance of CRBP-1 expression in G1 and partially in G2 endometrioid carcinomas suggests possible adjuvant pharmacological interventions using retinoid derivatives. In this sense, screening for CRBP-1 expression may represent an important prerequisite for pharmacological strategies aimed at influencing endometrial cancer cell growth through an increase of retinoic acid bioavailability. ${ }^{13}$ Moreover, modulation of CRBP-1 expression may represent a potential target of therapeutic strategies aimed to increase intracellular retinol bioavailability and thus arrest the progression of endometrial cancer.

In conclusion, reduced CRBP-1 expression is associated with the progression of endometrial carcinoma to higher grades. Furthermore, CRBP-1 immunodetection can be considered an additional useful tool for grading of endometrial carcinoma and may help to detect areas of differentiation, which cannot be easily identified by routinary histological examination. Further studies are necessary to define the biological role of different patterns of CRBP-1 expression and possible implications in pharmacological strategy aimed to counteract the progression of endometrial cancer.

\section{Acknowledgements}

We thank Alfredo Colantoni, Caterina Marcelli and Luciana Santangelo for their accurate technical work during the preparation of the manuscript.

\section{References}

1 Blomhoff R. Transport and metabolism of vitamin A. Nutr Rev 1994;52:S13-S23.

2 Underwood BA. Vitamin A and cancer prevention conference-an introduction. J Natl Cancer Inst 1984; 73:1371-1372.

3 Boettger-Tong HL, Stancel GM. Retinoic acid inhibits oestrogen-induced uterine stromal and myometrial cell proliferation. Endocrinology 1995;136:2975-2983.

4 Wolbach SB, Howe PR. Nutrition classics. J Exp Med 1925;42:753-777.

5 Wolbach SB, Howe PR. Tissue changes following deprivation of fat-soluble A vitamin. Nutr Rev 1978; 36:16-19.

6 Ong DE. Cellular transport and metabolism of vitamin A: role of the cellular retinoid-binding proteins. Nutr Rev 1994;52:24-31.

7 Napoli Jl, Posh KP, Fiorella PD, et al. Physiological occurrence, biosynthesis and metabolism of retinoic acid: evidence for roles of cellular retinol-binding protein (CRBP) and cellular retinoic acid-binding protein (CRABP) in the pathway of retinoic acid homeostasis. Biomed Pharmacother 1991;45:131-143.

8 Vogel S, Mendelsohn CL, Mertz JR, et al. Characterization of a new member of the fatty acid-binding protein family that binds all-trans-retinol. J Biol Chem 2001; 276:1353-1360.

9 Napoli JL. Biosynthesis and metabolism of retinoic acid: roles of CRBP and CRABP in retinoic acid: roles of CRBP and CRABP in retinoic acid homeostasis. J Nutr 1993;123:362-366.

10 Napoli JL. A gene knockout corroborates the integral function of cellular retinol-binding protein in retinoid metabolism. Nutr Rev 2000;58:230-241.

11 Farias EF, Ong DE, Ghyselinck NB, et al. Retinolbinding protein I, a regulator of breast epithelial retinoic acid receptor activity, cell differentiation, and tumorigenicity. J Natl Cancer Inst 2005;97:21-29.

12 Cvetkoviæ D, Williams SJ, Hamilton TC. Loss of cellular retinol-binding protein 1 gene expression in microdissected human ovarian cancer. Clin Cancer Res 2003;9:1013-1020.

13 Lotan R. A crucial role for cellular retinol-binding protein I in retinoid signaling. J Natl Cancer Inst 2005;97:3-4.

14 Siddiqui NA, Loughney A, Thomas EJ, et al. Cellular retinoid binding proteins and nuclear retinoic acid receptors in endometrial epithelial cells. Hum Reprod 1994;8:1410-1416.

15 Dallenbach-Hellweg G. Histopathology of the Endometrium. Springer-Verlag and Heidelberg: Berlin-New York, 1981, pp 159-216.

16 Neuville P, Geinoz A, Benzonana G, et al. Cellular retinol-binding protein-1 is expressed by distinct subsets of rat arterial smooth muscle cells in vitro and in vivo. Am J Pathol 1997;150:509-521.

17 Orlandi A, Ferlosio A, Ciucci A, et al. Cellular retinolbinding protein-1 expression in endometrial stromal cells: physiopathological and diagnostic implications. Histopathology 2004;45:511-517.

18 Jemal A, Murray T, Ward E, et al. Cancer statistics, 2005. CA Cancer J Clin 2005;55:10-30.

19 Amant F, Moerman P, Neven P, et al. Endometrial cancer. Lancet 2005;366:491-505.

20 Silverberg SG, Kurman RJ. Tumors of the Uterine Corpus and Gestational Trophoblastic Disease. In Atlas 
of Tumor Pathology. AFIP: Washington, DC, 1991, pp 47-89.

21 Clement PB, Young RH. Endometrioid carcinoma of the uterine corpus: a review of its pathology with emphasis on recent advances and problematic aspects. Adv Anat Pathol 2002;9:145-184.

22 Ellenson $\mathrm{LH}, \mathrm{Wu}$ TC. Focus on endometrial and cervical cancer. Cancer Cell 2004;5:533-538.

23 Mutter GL, Lin MC, Fitzgerald JT, et al. Altered PTEN expression as a diagnostic marker for the earliest endometrial precancers. J Natl Cancer Inst 2000;92: 924-930.

24 Orlandi A, Ferlosio A, Ciucci A, et al. Cellular retinolbinding protein-1 expression in endometrial stromal cells: physiopathological and diagnostic implications. Histopathology 2004;45:511-517.

25 Kanaya T, Kyo S, Maida Y, et al. Frequent hypermethylation of MLH1 promoter in normal endometrium of patients with endometrial cancers. Oncogene 2003;22: 2352-2360.

26 Prat J. Prognostic parameters of endometrial carcinoma. Hum Pathol 2004;35:649-662.

27 DiSaia PJ, Creasman WT, Boronow RC, et al. Risk factors and recurrent patterns in Stage I endometrial cancer. Am J Obstet Gynecol 1985;151:1009-1015.

28 Morrow CP, Bundy BN, Kurman RJ, et al. Relationship between surgical-pathological risk factors and outcome in clinical stage I and II carcinoma of the endometrium: a Gynecologic Oncology Group study. Gynecol Oncol 1991;40:55-65.

29 Bokhman JV. Two pathogenetic types of endometrial carcinoma. Gynecol Oncol 1983;15:10-17.

30 Kurman RJ (ed). Blaustein's Pathology of the Female Genital Tract, 5th edn. Springer-Verlag: New York, 2002, pp 467-503.

31 Wilson TO, Podratz KC, Gaffey TA, et al. Evaluation of unfavorable histologic subtypes in endometrial adenocarcinoma. Am J Obstet Gynecol 1990;162:418-423; discussion 423-426.

32 Matias-Guiu X, Catasus L, Bussaglia E, et al. Molecular pathology of endometrial hyperplasia and carcinoma. Hum Pathol 2001;32:569-577.

33 Tashiro $\mathrm{H}$, Isacson $\mathrm{C}$, Levine $\mathrm{R}$, et al. p53 gene mutations are common in uterine serous carcinoma and occur early in their pathogenesis. Am J Pathol 1997;150:177-185.
34 Bergeron C, Nogales FF, Masseroli M. A multicentric European study testing the reproducibility of the WHO classification of endometrial hyperplasia with a proposal of a simplified working classification for biopsy and curettage specimens. Am J Surg Pathol 1999;23: 1102-1108.

35 Shutter J, Wright Jr TC. Prevalence of underlying adenocarcinoma in women with atypical endometrial hyperplasia. Int J Gynecol Pathol 2005;24: 313-318.

36 Liu RZ, Denovan-Wright EM, Degrave A, et al. Spatiotemporal distribution of cellular retinol-binding protein gene transcripts (CRBPI and CRBPII) in the developing and adult zebrafish (Danio rerio). Eur J Biochem 2004;271:339-348.

37 Tannous-Khuri L, Hillemanns $\mathrm{P}$, Rajan $\mathrm{N}$, et al. Expression of cellular retinol- and cellular retinoic acid-binding proteins in the rat cervical epithelium is regulated by endocrine stimuli during normal squamous metaplasia. Am J Pathol 1994;144: 148-159.

38 Hillemanns $\mathrm{P}$, Tannous-Khuri L, Koulos JP, et al. Localization of cellular retinoid-binding proteins in human cervical intraepithelial neoplasia and invasive carcinoma. Am J Pathol 1992;141:973-980.

39 Kuppumbatti YS, Bleiweiss IJ, Mandeli JP, et al. Cellular retinol-binding protein expression and breast cancer. J Natl Cancer Inst 2000;92:475-480.

40 Arapshian A, Bertran S, Kuppumbatti YS, et al. Epigenetic CRBP downregulation appears to be an evolutionarily conserved (human and mouse) and oncogene-specific phenomenon in breast cancer. Mol Cancer 2004;3:13.

41 Jeronimo C, Henrique R, Oliveira J, et al. Aberrant cellular retinol binding protein 1 (CRBP1) gene expression and promoter methylation in prostate cancer. J Clin Pathol 2004;57:872-876.

42 Esteller M, Guo M, Moreno V, et al. Hypermethylationassociated Inactivation of the Cellular Retinol-Binding-Protein 1 Gene in Human Cancer. Cancer Res 2002;62:5902-5905.

43 Rousseau C, Pettersson F, Couture MC, et al. Nterminal of the estrogen receptor (ERalpha) mediates transcriptional cross-talk with the retinoic acid receptor in human breast cancer cells. J Steroid Biochem Mol Biol 2003;86:1-14. 